\title{
Information seeking and avoidance behavior in school library distance learning
}

\author{
Yunfei Du \\ Assistant Professor, College of Information, Department of Library and Information Sciences, \\ University of North Texas, Denton, TX 76203, U. S. A. \\ Email $\underline{\text { Yunfei.du@unt.edu }}$
}

\begin{abstract}
Library science students in school librarianship were surveyed to determine their information seeking and avoidance behaviors in Web-based online environments. Two coping styles were identified among students. Barriers to student online collaboration, such as individual preferences, concerns on efficiency, and lack of mutual trust, were observed.
\end{abstract}

\section{Introduction}

Previous studies found individuals may behave differently in a group environment versus when they are alone (Stueart \& Moran, 2007, p. 393). In education literature, team-based learning, or collaborative learning, has been accepted as an effective means to enhance education (Farmer, 1999; Johnson \& Johnson, 1999). While employers appreciate team work in professional settings, faculty might hesitate to integrate collaborative activities into curriculum, partly due to uncertainty of student behaviors in group environments. From students' perspectives, group projects may be completed by one or two individuals, while the rest of the team members are idle. Online education often makes collaboration even harder as students may never meet face-to-face, since face-to-face meetings are important factors in promoting individual interactions and success (Hunter, 2009, p. 71).

Team-based work is essential in performing daily school library services to teachers and students, but it has not been widely adopted in school librarian education. Hence, it may be beneficial to expand current educational curricula to include the skills of effective teamwork in order to prepare library students for reallife collaborative projects. Such approach may help in-service school librarians to design more interactive library programs. To accomplish this goal, it may help for educators and librarians to gain a better understanding of how to spot student who have a propensity for team work. Currently, little is known about how to identify students who tend toward collaborative learning online as opposed to those who avoid collaboration, particularly in school library distance education coursework. The purpose of this project is to identify potential avoidance behaviors exhibited by students in online classrooms of a school library program. Of particular interest is the question of how individual coping styles in information seeking and avoidance will influence collaborative learning in a Web-based collaborative learning environment. Copying styles are idefined as monitors (seekers) and blunters (avoiders) in this paper.

This paper addresses the following research questions:

- How to identify collaborators in an online learning environment using a coping behavior scale?

- To what extent will different coping styles affect school library students' tendencies to collaborate, whether the collaboration is required or optional?

\footnotetext{
Literature review

Collaborative learning

Computer-assisted collaborative learning theories are based on two important theoretical models: social cognitive theory (Bandura, 1986) and social development theory (Vygotsky \& Cole, 1978). Social cognitive theory emphasizes the importance of observing others and imitating the observed action during the learning process. Social development theory suggests that social interaction, beyond observational learning, plays a fundamental role in the development of cognition. Social development theory was based on the context of language learning in children.
} 
Similar terms have been used interchangeably in education literature for learning collaboratively, notably cooperative learning (Johnson \& Johnson, 1999), student team learning (Slavin, 1999), group investigation (Sharan \& Sharan, 1992), and collaborative learning (Barnes, Britton, \& Torbe, 1990). Farmer (1999) stated that cooperative learning emphasized structured groups of people who have a specific learning task to accomplish together, while collaborative learners may not need a deep-seated relationship with their peers in order to work with them. Collaborative learning may improve students' self-esteem, attitude toward school, and ability to work with others (Farmer, 1999, p. 1).

\section{Information Avoidance}

Information scientists, while studying information seeking behavior, found that people who are stressed may not seek information actively, and in some cases they may avoid all forms of information (Case, 2005). A widely used tool to measure information avoidance is Suzanne M. Miller's coping styles theory (1987). The theory suggests that when facing stressful situations, people differ in ways of dealing with information. Monitors try to decrease the stress by actively seeking, in effect, keeping them alert. Blunters deal with the adverse events by distracting themselves and avoiding information in order to protect themselves. Miller Behavior Style Scale (MBSS) differentiates participants as either monitors or blunters based on their answer to scenario-based questions (Baker, 1996). The MBSS has been validated by previous researchers, particularly regarding information behavior within consumer health scenarios. Baker (2006) conducted literature review on Miller's theory on monitoring and blunting and has published about its use in healthrelated information seeking issues (Baker \& Pettigrew, 1999). Information avoidance might link to another concept called Learned Helplessness (Peterson, Maier, \& Seligman, 1993), a psychological phenomenon in which humans or animals learn to behave helplessly and avoid negative circumstances, even when the positive circumstances are present.

\section{Method}

The author utilized a survey adapted from the MBSS to evaluate how coping styles may influence online students' tendencies to collaborate. The coping style is an individual's tendency, under stress, to either monitor or blunt external information tasks (Miller, 1987; Baker, 2006). MBSS contains four questions. Each question has eight statements reflecting either monitoring (seekering) or bluntering (avoidering) behaviors. Participants choose the statements that apply to themselves. For example, under such a scenario - "vividly imagine that you are on an airplane, thirty minutes from your destination, when the plane unexpectedly goes into a deep dive and then suddenly levels off", a monitor may "listen carefully to the engines for unusual noises and watch the crew to see if their behavior is out of the ordinary", while a blunter may "settle down and read a book or magazine or write a letter".

The author created original four questions to survey the tendency of online collaboration as a result of social norms and situational needs. Social norm, or subjective norm, is a term that is defined here as the peer pressure from inside and outside collaborative groups (Ajzen and Fishbein, 1980, p. 8). Situational norm can be measured via the likelihood of a particular behavior resulting from the influence of peer-pressure. Situational needs include individual's socio-economic status, anxiety, and cultural background. In an online learning environment, situational needs may be reflected by whether a subject will take an action if he/she is required to or has an option to perform certain actions. The survey were attached as Appendix A. Question 1 from appendix A was on social norm, and questions $2-4$ were related to the construct of situational needs.

School library graduate students enrolled in online classes in an ALA accredited Masters program participated in the survey. Results from students' answers were analyzed using a one-way Analysis of Variance (ANOVA), exploring whether coping styles (monitor vs. blunter) will influence students' tendency to collaborate. The survey also collected students' comments on online collaboration.

\section{Results}

One hundred and twenty-one school library students participated in the survey in fall 2009. Among these participants, 5 were males and the rest were females. Table 1 illustrates the descriptive statistics of the first questions. 
Table 1. Descriptive statistics

\begin{tabular}{ll}
\hline Question Items & Mean (SD) \\
\hline Q1. (Collaboration-optional) & $3.38(1.37)$ \\
Q2. (Collaboration-required) & $3.23(1.27)$ \\
Q3. (quickness-to-collaborate-optional) & $3.31(1.11)$ \\
Q4. (quickness-to-collaborate-required) & $4.5(1.29)$ \\
\hline
\end{tabular}

Note: Mean scores are based on a scale from 1 to 5.

The age of the students was varied thus: only 4 students were 26 or younger; 38 of them were 26 to 35,44 students were 36 to 45 years old, 27 were 45 to 55 , and 8 students were age 56 or higher. Students were almost equally distributed concerning courses they have completed, with $25(20 \%)$ of them having finished 0 to 3 courses, $36(31 \%)$ having taken 4 to 6 courses, 31(25\%) having taken 7 to 9 courses, and $29(24 \%)$ having completed 10 or more courses.

All 121 students answered the four questions that were adapted from the MBSS. Each question has four choices exemplifying monitors and four exemplifying blunters. The mean score for monitors was $8.88(\mathrm{SD}=$ 2.65). Figure 1 illustrates the distribution of scores of monitors.

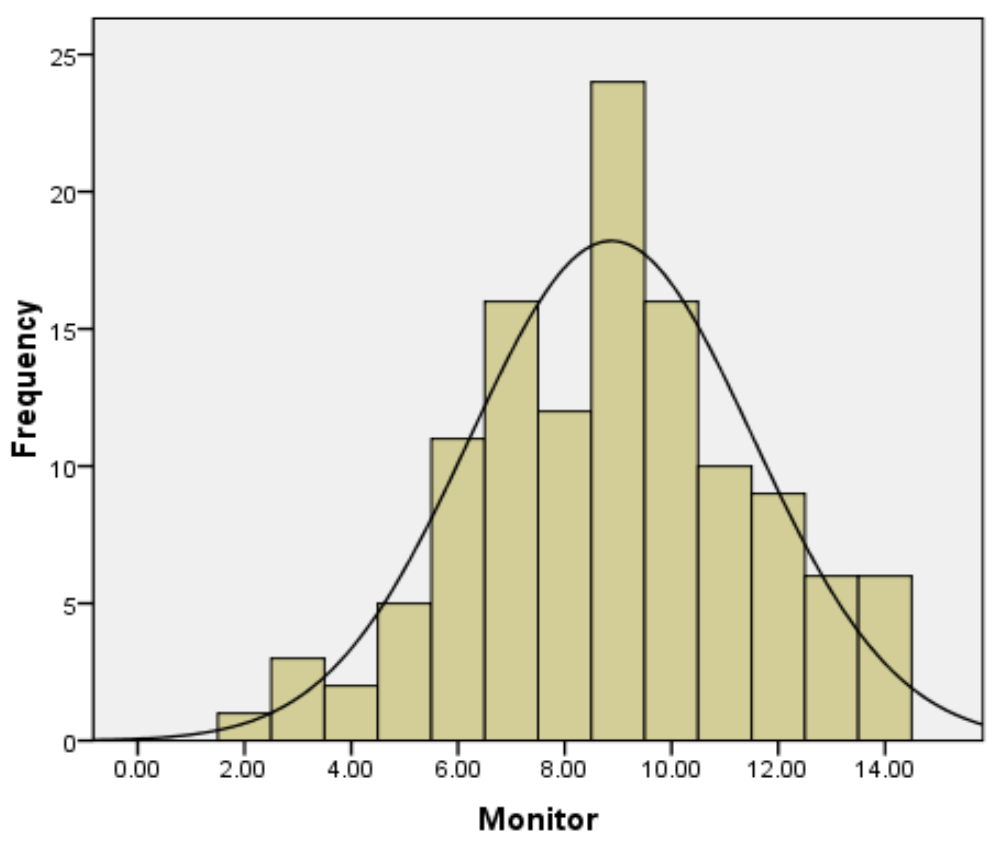

Figure 1. Distribution of Monitors

The MBSS scale also yielded the scores representing blunters. The mean score for blunters was 4.12 (SD = 2.17). Figure 2 demonstrates the histograms of "blunters".

(C) 2010 IASL, SLAQ and therein by the authors. Diversity Challenge Resilience: School Libraries in Action Proceedings of the $12^{\text {th }}$ Biennial School Library Association of Queensland, the $39^{\text {th }}$ International Association of School Librarianship Annual Conference incorporating the $14^{\text {th }}$ International Forum on Research in School Librarianship, Brisbane QLD Australia, 27 September - 1 October 2010. 


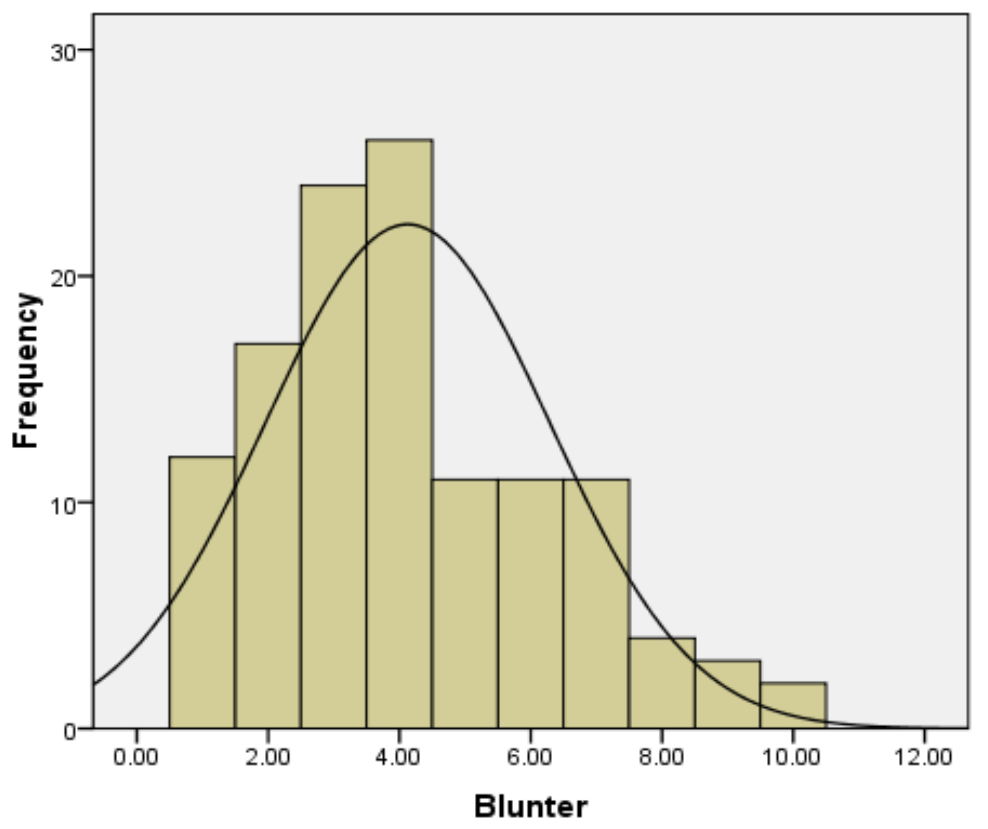

Figure 2. Distribution of Blutners

In this sample, more students chose question items reflective of monitors than blunters, representing a group of students who pay attention to class assignments and demonstrating a willingness to cope with situations. The author adopted Baker's approach (1996) by separating the subjects in two groups based on the mean score of the difference between monitors and blunters. Among the participants $65(46 \%)$ were above the mean score and categorized as information-seekers, while the remaining of $56(54 \%)$ were categorized as information-avoiders.

To answer question 2, ANOVA tests were conducted to estimate whether the grouping information of coping styles (monitors vs. blunters) influences students' intentions to collaborate. However, ANOVA tests did not yield statistical significance on all four questions on students' intentions to collaborate, whether collaboration was optional or required $(\mathrm{Q} 1, \mathrm{~F}=.21$, sig. $=.87 ; \mathrm{Q} 2, \mathrm{~F}=.42$, sig. $=.52 ; \mathrm{Q} 3, \mathrm{~F}=2.25$, sig. $=.14 ; \mathrm{Q} 4, \mathrm{~F}=.02$, sig. $=.91)$. The ANOVA tests failed to reject the null hypothesis. There is no statistical difference among monitors and blunters in regard to their tendency to collaborate.

\section{Content Analysis}

Content analysis of all student comments revealed four themes: reasons behind being a monitor, reasons behind being a blunter, benefits of collaborating, and barriers to collaborating in online learning environments.

A majority of students clearly indicated they had a monitor coping style when dealing with course work. Here are some examples of students' comments:

"I don't like to wait until the last minute on anything. I make it a habit to start on it in advance so that it is finished before the deadline."

"I don't want to depend on someone else and not know until the last minute what the end product will be. It leaves no opportunity to make revisions if necessary."

"It is important to jump in and get started. Waiting to the last minute puts pressure on everyone involved in the learning; rather beginning and setting out some expectations actually encourages the collaborative efforts and allows more time to visit back and forth." 
Some students made some statements suggesting a blunting coping style in Web-based learning:

"Intellectually, I prefer sooner. In reality I seem to need the pressure of the last minute."

"Procrastination is truly a hindrance to our fullest potential, yet it is in our nature to prolong or wait until the last minute."

"I like to take my time and be thorough. This usually results in using all the time available since online learning environments have strict (and sometimes aggressive) deadlines."

Some students stated the benefits of collaboration in learning:

"I like to see what others are finding then expand it by commenting to their post, or taking the research to another level."

"I like to work with others since I know I will learn from them. I like to share what I do know."

"When everyone is engaged it is easier to motivate each other to work faster."

"Peer assignments are just as essential to learning as the individual ones. It does take someone stepping out and taking the lead to keep everyone on track. Once this is done, early deadlines can be set to allow for the straggler."

Students' concerns on collaboration can be summarized into one of the three themes: personal preference, efficiency, and trust. Some students made comments on personal preference on collaboration:

"I have found that I am a more analytical learner than most and so in regard to this question, it would depend on the assignment. I enjoy working with others and feel there is value in it, however sometimes it limits the depth of your own learning."

"Collaboration is essential yet a sense of individuality is lost in the process, hence sometimes a bit difficult."

The majority of the student concerns are related to efficiency of the group project:

"Sometimes it's easier and quicker to do it yourself."

"Online learning enables students from anywhere in the world to take the same course. I am 7 hours off of the time zone where most of my classmates reside, and this makes collaboration very difficult! We can exchange messages but actually talking to one another is sometimes difficult. Thus, if given a choice, I like to discuss work but prefer submitting individual assignments."

"I have found that the times when I work in a group I end up doing most of the work and no one actually collaborates. Therefore I prefer to work alone."

Some students emphasized the importance of trusting each other when collaborating online:

"It would depend on the nature of the assignment and if I had any peers in the class that I knew."

"It depends. I almost always prefer to work independently unless I know the others in the group and know that they are serious about the assignment."

The qualitative feedback above provided tentative explanations as to why students prefer to be monitors during the process of collaborative class projects. It is evident they are concerned that some group members will avoid the responsibilities of contributing to the group.

(c) 2010 IASL, SLAQ and therein by the authors. Diversity Challenge Resilience: School Libraries in Action Proceedings of the $12^{\text {th }}$ Biennial School Library Association of Queensland, the $39^{\text {th }}$ International Association of School Librarianship Annual Conference incorporating the $14^{\text {th }}$ International Forum on Research in School Librarianship, Brisbane QLD Australia, 27 September - 1 October 2010 . 


\section{Discussions}

To answer the first research question, this study explored how individual coping styles, in terms of monitoring and blunting, can be used to identify students' willingness to collaborate in a Web-based learning environment. The combination of quantitative and qualitative methods suggested that, in this group, more of the students were monitors than blunters. They tend to pay attention to the deadlines of asynchronous online learning. They were willing to take the lead when some group members do not contribute sufficiently. Since students were school librarians, usually having some teaching experience, their professional training may have influenced their coping style, resulting in their taking more proactive roles.

The barriers to collaboration are multi-facets. Teachers and in-service school librarians can nurture collaboration by addressing individual resistance to collaborate, design interactive content to make sure the collaboration is productive and efficient, and take measures to build trust among the groups.

No statistical significance has been found on students' tendencies to collaborate (i.e., collaboration-optional, collaboration- required, quickness-to-collaborate-optional, and quickness-to-collaborate-required), suggesting coping style plays a relatively minor role in actually online learning. A good quality of graduate students, who are also professional school teachers, might skewed the results toward monitoring coping style.

\section{Conclusions}

The preliminary results yielded first-hand data for educators and in-service teacher librarians to incorporate meaningful collaborative student activities into the curriculum. As students suggested, online collaboration may be perceived as inefficient, causing the loss of time and student dissatisfaction. It is necessary to build trust among collaborators before real collaboration begins. A match between students' personalities and learning styles seem to be another useful way to successful collaboration.

The limitations of this study include a small sample size, which is explorative in nature, and the sample group being relatively homogeneous monitors. The survey should be administered to new groups of students to validate the results from a more diverse group of students.

The results of this study confirmed partially Stueart and Moran's recommendation (2007) of important components such as building teams, good communication, appropriate leadership, clear goals, and loyalty. Future studies should also consider these important aspects when looking for factors to build team-based learning projects for school library distance learners.

\section{References}

Ajzen, I., \& Fishbein, M. (1980). Understanding attitudes and predicting social behavior. Englewood Cliffs, NJ: Prentice-Hall.

Baker, L. M. (1996). A Study of the nature of information needed by women with multiple sclerosis. Library and Information Science Research, 18(1), 67-81.

Baker, L. M. (2006). Monitoring and blunting. In K. E. Fisher, S. Erdelez, \& L.E.F. McKechnie (eds), Theories of information behavior. Medford, NJ: Information Today.

Baker, L. M. \& Pettigrew, K. E. (October 1999). Theories for practitioners: Two frameworks for studying consumer health information-seeking behavior. Bulletin of the Medical Library Association, 87(4). Accessed April 29, 2010 from http://www.pubmedcentral.nih.gov/articlerender.fcgi?artid=226619

Bandura, A. (1986). Social foundations of thought and action: A social cognitive theory. Englewood Cliffs, NJ: Prentice-Hall.

Barnes, D., Britton, J., \& Torbe, M. (1990). Language, the learner, and the school (4 ${ }^{\text {th }}$ ed). Portsmouth, NH: Boynton/Cook

(C) 2010 IASL, SLAQ and therein by the authors. Diversity Challenge Resilience: School Libraries in Action Proceedings of the $12^{\text {th }}$ Biennial School Library Association of Queensland, the $39^{\text {th }}$ International Association of School Librarianship Annual Conference incorporating the $14^{\text {th }}$ International Forum on Research in School Librarianship, Brisbane QLD Australia, 27 September - 1 October 2010. 
Case, D. (2005). Avoiding versus seeking: The relationship of information seeking to avoidance, blunting, coping, dissonance, and related concepts. Journal of Medical Library Association, 93(3), 353-362.

Farmer, L. S. J. (1999). Cooperative learning activities in the library media center. Englewood, CO: Libraries Unlimited.

Hunter, J. (2009). One more thing: Faculty response to increased emphasis on project teams in undergraduate engineering education. Unpublished doctoral dissertation, University of Arizona.

Johnson, D. W., \& Johnson, R. T. (1999). Making cooperative learning work. Theory into Practice, 38(2), 67-73.

Miller, S. M. (1987). Monitoring and blunting: Validation of a questionnaire to assess styles of information seeking under threat. Journal of Personality and Social Psychology, 52(2), 345-353.

Peterson, C., Maier, S. F., Seligman, M. E. P. (1993). Learned helplessness: A theory for the age of personal control. New York: Oxford University Press

Sharan, Y., \& Sharan, S. (1992). Expanding cooperative learning through group investigation. NY: Teachers College Press.

Slavin, R. (1999). Student teams-achievement division. In S. Sharan (Ed.), Cooperative learning methods (pp. 3-19). Westport, CT: Praeger Publishers.

Stueart, R. D., \& Moran, B. (2007). Library and information center management. Westport, CT: Library Unlimited.

Vygotsky, L. S. \& Cole, M. (1978). Mind in society: The development of higher psychological processes. Cambridge, MA: Harvard University Press. 


\section{Appendix A. Collaborative Learning Survey}

1. Given an option to collaborate with your peers on assignments, if you notice others begin working collaboratively, how likely are you to find yourself inclined to do the same? $(1=$ least like you, $5=$ most like you).

2. Given an option to collaborate with your peers on assignments, rate how fast you prefer to finish them ( $1=$ to be completed as soon as possible, $5=$ to be completed at the last minute).

3. If you are required to work collaboratively with peers on an assignment, rate how promptly you feel inclined to work on it $(1=$ take the lead as fast as possible, $5=$ wait for someone else to take the initiative).

4. If you are required to work collaboratively with peers on an assignment, rate how likely it will be completed $(1=$ very unlikely, $5=$ very likely $)$.

5. Background information: Your gender

Male

Female

6. Age group that you belong to:

18 to 25

26 to 35

36 to 45

45 to 55

56 or above

7. How many courses have you completed in your program:

0 to 3

4 to 6

7 to 9

10 or more

(Questions 8 - 11 were adapted from MBSS and omitted from this paper)

\section{Statement of Originality}

This statement certifies that the paper above is based upon original research undertaken by the author and that the paper was conceived and written by the author(s) alone and has not been published elsewhere. All information and ideas from others is referenced. 